\title{
MOVIMENTOS FEMINISTAS NO BRASIL E SUA AÇÃO INSUBMISSA FRENTE AO GOLPE DE 2016
}

\author{
FEMINIST MOVEMENTS IN BRAZIL AND ITS INSUBMISSA ACTION \\ AGAINST THE BEAT 2016
}

\author{
Maria Mary Ferreira ${ }^{1}$
}

\begin{abstract}
RESUMO
Os recentes acontecimentos que marcam o Brasil no processo e após o impeachment de Dilma Rousseff acirraram um amplo debate sobre a condição da mulher neste País, cuja cultura política é reconhecidamente patriarcal. As ações do movimento feminista demonstraram que o golpe revestido de impeachment, no qual se articularam os setores mais conservadores do País: mídia, o Congresso Nacional, o judiciário, capitaneado pelo Supremo Tribunal Federal e a elite econômica, mostraram que a misoginia, o machismo, o sexismo, são parte de uma cultura patriarcal que não ultrapassou os muros do Século XX. As ofensivas dirigidas à então Presidenta Dilma através de redes sociais e de forma mais direta no episódio da Copa do Mundo em 2014, surpreendeu pela grosseria, misoginia e violência dos homens sobre as mulheres. Uma violência que como se viu ultrapassa os espaços do privado para publicizar de forma inesperada e cruel contra uma mulher que, naquele momento representava a sociedade brasileira tendo em vista sua eleição em 2010 e reeleição em 2014. A ação e reação dos movimentos feministas que, ao longo das décadas se singularizaram pela radicalidade, pela força transgressora das várias articulações, se fez presente em atos de norte a sul do País. Mostrando um feminismo revigorado, criativo, transgressor, articulado e renovado. Neste artigo apresentamos uma reflexão sobre as correntes que ajudam a compreender como os movimentos feministas se movimentaram no País através de várias frentes de lutas. Foram estas frentes que desnudaram e desmascararam o golpe. Os movimentos afirmaram seu potencial de luta de insubmissão e descontentamento em relação à situação de uma mulher que, naquele momento, representava todas as mulheres oprimidas e vítimas do patriarcado. O estudo ora apresentado é parte de reflexões que se dão no contexto acadêmico e na luta feminista como ativista, e como pesquisadora. Metodologicamente o estudo se caracteriza como qualitativo e perspectiva dialética, dada a dimensão das análises que buscam pensar o movimento feminista como movimento político, considerado um dos pilares da emancipação as mulheres, responsável por protagonizar ações políticas de intervenção na realidade.
\end{abstract}

Palavras-chave: Feminismos; Mulheres; Política; Brasil; Dilma Rousseff

\begin{abstract}
The recent events that mark Brazil in the process and after the impeachment of Dilma Rousseff stimulated a wide debate on the condition of the woman in this Country, whose political culture is recognized patriarchal. The actions of the feminist movement have shown that the impeachment coup, in which the most conservative sectors of the country were articulated: the media, the National Congress, the judiciary, headed by the Federal Supreme Court and the economic elite, showed that misogyny, , sexism, are part of a patriarchal culture that did not go beyond the walls of the 20th century. The offensives addressed to the then President Dilma through social networks and more
\end{abstract}

\footnotetext{
${ }^{1}$ Professora Associada do Departamento de Biblioteconomia e do Programa de Pós Graduação em Políticas Públicas da Universidade Federal do Maranhão; Doutora em Sociologia pela UNESP/FCLAr. Atualmente faz Pós-Doutorado na Universidade do Porto/Portugal com bolsa da Fundação de Amparo à Pesquisa e ao Desenvolvimento Científico e Tecnológico do Maranhão (FAPEMA)
} 
directly in the episode of the World Cup in 2014, surprised by the rudeness, misogyny and violence of men over women. A violence that, as we have seen, goes beyond the private spaces to publicize in an unexpected and cruel way against a woman who, at that moment, represented Brazilian society with a view to her election in 2010 and re-election in 2014. The action and reaction of the feminist movements, over the decades they have distinguished themselves by radicality, by the transgressive force of the various articulations, has been present in acts from north to south of the Country. Showing a feminism reinvigorated, creative, transgressive, articulated and renewed. In this article we present a reflection on the currents that help to understand how the feminist movements have moved in the Country through several fronts of struggles. It was these fronts that stripped and unmasked the coup. The movements affirmed their potential of struggle of discontent and discontent in relation to the situation of a woman who, at that moment, represented all oppressed women and victims of patriarchy. The study presented here is part of reflections that take place in the academic context and in the feminist struggle as an activist, and as a researcher. Methodologically, the study is characterized as a qualitative and dialectical perspective, given the dimension of the analyzes that seek to think of the feminist movement as a political movement, considered one of the pillars of women's emancipation, responsible for carrying out political intervention actions in reality.

Keywords: Feminisms; Women; politics; Brazil; Dilma Rousseff

\section{INTRODUÇÃO}

Dois anos após o golpe de 2016, que retirou do poder a Presidenta eleita Dilma Rousseff, a sociedade brasileira vive a polarização dos debates acalorados sobre as eleições de outubro próximo. Neste cenário de disputa eleitoral, os movimentos sociais continuam a se levantar para trazer a público seu descontentamento com os rumos que o País tomou após o impeachment de Dilma Rousseff. Dentre os movimentos destacamos os movimentos feministas que têm contribuído para um debate rico e articulado, demonstrando e fazendo jus à sua história revolucionária.

Reconhecido por seu caráter transgressor, mobilizador e articulador o movimento feminista é protagonista das lutas por direitos, cidadania, dignidade, justiça para as mulheres, seja nas sociedades de classe, seja nas sociedades comunistas, socialista. Sua luta histórica contra os determinismos biológicos que naturalizou a inferioridade das mulheres, sob argumentos de que eram frágeis, maternavam e não estavam, portanto, afeitas a determinadas tarefas e responsabilidades políticas, foram argumentos rechaçados na luta feminista na maior parte das nações do mundo. No Brasil não foi diferente.

A luta das brasileiras segue caminho das francesas, inglesas, americanas, chilenas. Luta que perpassa os espaços do privado para se inserir no mundo público e, gradativamente, foi se constituindo como um feminismo com as singularidades deste imenso e contrastante País. A 


\section{novistet

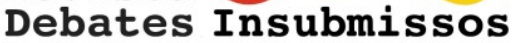

polarização inicial entre "luta geral versus luta específica" que nos anos setenta dividiu os movimentos feministas de alguma maneira, se reunifica em torno de bandeiras comuns no combate à violência contra a mulher, no debate sobre corpo, sexualidade, aborto entre outros temas.

Os tempos mudaram, poderíamos dizer, as mulheres conquistaram muitos direitos, hoje são maioria nos cursos superiores e nos cursos de Pós-Graduação, alcançaram vários espaços no mercado de trabalho, porém, ao avaliar os indicadores de emprego e renda, a violência de gênero e a sub-representação de mulheres no poder, observa-se que não conseguiram ultrapassar níveis de respeito e igualdade salarial e política, tendo em vista que a política, a economia, são lugares ainda pouco acessíveis às brasileiras.

Os recentes acontecimentos que se desdobraram no impeachment de Dilma Rousseff, primeira mulher eleita e reeleita presidenta deste País continental, em processo coberto de falhas e argumentos frágeis, todos insustentáveis, conforme processo que a inocentou e inúmeras matérias veiculadas em diversos Jornais do País e redes sociais ${ }^{2}$ a exemplo do Jornal O Globo ${ }^{3}$, O Estadão ${ }^{4}$, demonstram essa assertiva. O mais paradoxal deste episódio é o fato de que logo após o impeachment o senado legalizou as "pedaladas"5.

O episódio, muito caro à nação brasileira, nos faz lembrar as palavras de Perrot:

[...] o mundo público, sobretudo o econômico e político é destinado aos homens, e é o mundo que conta. Esta definição de papéis clara e voluntarista, traduziu-se por uma retirada das mulheres de certos locais: a Bolsa, o Banco, os grandes mercados de negócio, o Parlamento, os clubes, círculos e café, grandes locais de sociabilidade masculina (PERROT, 2005, p.34).

Michelle Perrot estava se referindo às mulheres francesas do Século XIX, mas cabe perfeitamente às mulheres brasileiras do Século XXI, principalmente quando se analisa o processo do golpe de 2016. Entretanto, não se pode desconsiderar as reações dos movimentos feministas em diversas Regiões do País, que denotam a grandeza, consciência crítica e

\footnotetext{
${ }^{2}$ DILMA... (2016).

${ }^{3}$ PERÍCIA... (2016)

${ }^{4}$ FABRINI (2016)

${ }^{5}$ APÓS impeachment ... (2016)
} 
radicalidade deste movimento que promove pequenas revoluções de costumes e avança no debate político de repensar a democracia no Brasil.

Os pontos referidos até aqui são motivos a serem discutidos neste texto, cuja construção tem sido parte de reflexões construídas a partir de meus estudos, pesquisas, mas principalmente da militância que tento conciliar entre a vida acadêmica na universidade e nas ações do ativismo político que nunca deixei de estar. Embora alguns autores considerem inconciliáveis, considero que a militância alimenta a academia e vice- versa.

Para melhor compreensão deste trabalho, priorizei na sua primeira parte uma breve discussão sobre o histórico do feminismo e suas correntes, pois considero importante para compreender as diversas formas e linhas de atuação dos diversos grupos, redes, fóruns, etc. que atuam no Brasil. Na segunda parte do texto, ou melhor dizendo, no item três, apresento dados da atuação dos movimentos colhidos das redes sociais, sites e jornais que permitem acompanhar e avaliar a dimensão e ação dos vários feminismos no Brasil. Ao final do texto apresento algumas considerações mais conclusivas sobre o tema abordado.

\section{PARA ENTENDER O FEMINISMO NO BRASIL: UM POUCO DE HISTÓRIA E POLÍTICA}

Autoras como Alves (1980), Ferreira (2007), Costa (2009), entre outras, são unânimes em afirmar que os movimentos feministas no Brasil emergem na luta contra a ditadura nos anos sessenta e se fortalecem nos anos setenta e oitenta. A forma como os movimentos se organizaram nessas três décadas embora com variações em grande parte, se deram através de grupos de reflexão. As oficinas de modelagem, de autoexame, de desenho e colagem sobre corpo, sexualidade, prazer, erotismo, trouxeram uma forma criativa de autoconhecimento e de integração das mulheres independentemente de suas ideologias, classe social, raça e etnia.

Esta forma de organização contribuiu para criar uma relação de identidade entre as mulheres e possibilitou o descolamento da sexualidade da reprodução, configurando, assim, sua autonomia em relação à sexualidade. Essa prática notabilizou-se como um momento importante de autoconhecimento e de fortalecimento de um aprendizado integrador e transformador de fazer política onde se recusavam as hierarquias, a centralização e verticalização de decisões. 


\section{Revista \\ Debates Insubmissos}

É sempre bom lembrar que o debate sobre o corpo foi uma das questões centrais do discurso feminista: "Nossos corpos nos pertencem" esta frase expressou e inaugurou uma forma transgressora das feministas discutirem as relações de poder, relações estas que perpassavam os espaços públicos e privados. Na leitura de Scavone (2010, p. 49):

O discurso feminista se abria, então, para um debate político sobre o corpo ao afirmar suas diferenças, reivindicar seus direitos, praticar sua liberdade e se insurgir incansavelmente contra o controle social ao qual era submetido. A insubmissão contra um corpo assujeitado, medicalizado, à mercê de políticas morais, religiosas ou demográficas de Estado, fundadas na ideia de natureza, foi uníssona nos países do Norte nos anos 1970 e se espalhou pelo mundo.

Ao atuar de forma pouco convencional os movimentos feministas e as feministas incomodavam. Ao denunciar as contradições da sociedade patriarcal e ao expor suas ideias pautadas no ideal de liberdade e defesa intransigente dos direitos das mulheres. Para Ferreira, (2007, p. 38): esse movimento se contrapunha a “[...] esse modelo de sociedade ao defender um mundo mais partilhado, paritário cujas decisões deveriam também passar pelo pensamento das mulheres".

As pautas apresentadas pelas feministas à sociedade e ao Estado nos anos, setenta, oitenta, noventa, e mais recentemente, confirmam a radicalidade e intensidade deste movimento na luta por igualdade e cidadania para as mulheres.

A atuação do movimento nos últimos 50 anos, em várias frentes, de forma intensa e ininterrupta visavam tornar a política um espaço acessível às mulheres e através de sua ação política elevá-las à condição de sujeito de direitos. Os resultados podem ser mensurados no conjunto de políticas, programas e legislações que alteraram de forma substancial a vida das brasileiras nas últimas décadas. Dentre as muitas conquistas podemos destacar: a criação das Delegacias da Mulher, a licença maternidade de 120 dias, a implementação do aborto legal, as mudanças no Código Civil Brasileiro, o Pacto de Combate à Violência Doméstica, a criação das Varas da Família, e tantas outras conquistas. Referidas conquistas contribuíram em grande parte para recuperar a dignidade das mulheres, embora muitas pautas e várias reinvindicações ainda não tenham sido efetivadas, a exemplo da descriminalização do aborto e da paridade na participação política das mulheres nos espaços de poder. 


\section{Revista \\ Debates Insubmissos}

\subsection{As correntes que marcam a luta feminista no Brasil}

Existem muitas formas de classificar e explicar os feminismos que eclodiram no mundo e em especial no Brasil. Assim é que aqui faço uma síntese do que estudei e do que vivenciei ao longo de tantos anos de luta, embora não possa ser considerado uma unanimidade, haja vista as diferentes formas como tem sido vivenciado por mulheres de diferentes grupos sociais. Considerei, para melhor explicar a riqueza deste movimento, seis grandes correntes que marcam a luta das mulheres por direito e igualdade: Feminismo sufragista, Feminismo liberal ou da igualdade, Feminismo Marxista; Feminismo Radical, Feminismo da Diferença e da Pluralidade e Feminismo Negro.

Feminismo sufragista: esta corrente ou onda, como enfatizam algumas autoras, agrega os primeiros protestos de mulheres e homens pelo direito à cidadania, no qual o direito ao voto era o principal ponto de reivindicação. Os embates promovidos pelas sufragistas brasileiras no Século XIX nos leva a afirmar que a luta pelo voto é, em dias atuais e comparada à luta pela legalização do aborto. Foram muitas as protagonistas desta luta, dentre elas mencionamos: Bertha Lutz, Celina Viana, Alzira Soriano e muitas outras, que ficaram anônimas na história. No Maranhão a luta da professora Laura Rosa (1894-1976) que assinava crônicas com o pseudônimo de Violeta Campos, está transcrita nos jornais maranhense no início do Século XX exigindo o direito da mulheres ao sufrágio, fato que demonstra que este movimento ultrapassou as barreiras das distâncias geográficas.

Feminismo da igualdade ou feminismo liberal: caracteriza-se pela busca da igualdade entre homens e mulheres. Trata de construir a igualdade de gênero, porém não polarizava as contradições das relações de poder que impunham às mulheres posições subalternas. As relações de classe também não eram consideradas nesta corrente feminista como questão central. Para Melo e Thomé (2018, p.21):

[...] o feminismo liberal sustenta que homens e mulheres são iguais uns aos outros e, como tal, merecem direitos iguais". Esta corrente faz com que muitos acreditem que a luta feminista se resuma apenas pela igualdade de direitos.

Feminismo marxista: esta corrente trouxe muitas contribuições ao enfatizar que a situação de subalternidade das mulheres não será superada sem que se demova as relações de 
produção/relações capitalista. As feministas marxistas trazem o pensamento de Karl Marx, Engels, Lenin, Alexandra Kollontai entre outros, para explicar que a opressão das mulheres. "Ao contrário das feministas radicais, que veem o patriarcado como fonte da desigualdade de gênero, as feministas marxistas afirmam que o capitalismo é a sua causa" (MELO; THOMÉ, 2018, p.25). O pensamento de Alexandra Kollontai traduz de forma clara as diferenças de pensar os feminismos liberal e marxista ao enfatizar que:

As feministas lutam por direitos políticos. Mas aqui também os caminhos se separam. Para as mulheres burguesas, os direitos políticos são apenas uma forma possivelmente mais cômoda e sólida de encontrar um lugar em um mundo construído sobre a exploração dos trabalhadores. Para as mulheres trabalhadoras, é um degrau da escada difícil e pedregoso que leva ao desejado reino do trabalho. (KOLLONTAI, 1913, apud SCHNEIDER, 2017, p. 162163)

Feminismo radical: denuncia a perspectiva masculina fundamentada nas relações de poder que, por sua vez, permeiam todas as relações sociais. Esta corrente "cria uma teoria política e social da opressão das mulheres e busca olhar para as raízes desta opressão exercida pelo sistema patriarcal" (MELO; THOMÉ, 2018, p. 22) Considera e reconhece que a sexualidade é um aspecto central da opressão e submissão da mulher. Uma das grandes pensadoras desta corrente foi Simone de Beauvoir. Seu livro O Segundo sexo, marca e aprofunda este debate e exerce uma influência muito grande nos feminismos no Brasil.

Feminismo da Diferença e da Pluralidade: agrega um conjunto de impasses das diversas correntes sem perder de vista as características autônomas e libertárias do movimento feminista. Trabalha com a ideia de que somos fruto de uma cultura que molda homens e mulheres para exercerem papéis definidos pela sociedade patriarcal. Por este motivo esta corrente aposta e acredita em uma formação cultural que possa transformar e humanizar o mundo, respeitando as diferenças e construindo a igualdade de forma plural. Para Wallerstein (2004, p. 6):

Visto como pensamento da diferença, o feminismo aparece como um grande revisor da história. As relações entre feminismo e história são ricas, múltiplas e cheias de caminhos. O feminismo tem mostrado como a história, seguindo alguns interesses, apagou a mulher de suas páginas, fazendo que ela aparecesse apenas como um outro do homem. Imagens onde a mulher aparece "produtivamente" são simplesmente esquecidas. Mas uma das coisas que o 


\section{novistet \\ Debates Insubmissos}

feminismo nos mostra é que a história não é o destino, assim como o corpo também não o é.

Feminismo Negro: Traz à tona as contradições do feminismo liberal ao enfatizar que a sociedade tem cor. É uma corrente que tem suas raízes na luta das mulheres negras norteamericanas. Angela Davis é uma das pioneiras e um dos símbolos da luta das feministas negras, e no Brasil se destaca Lélia Gonzalez. Para as negras, a luta feminista perpassa a luta contra os racismos. Desse modo, denunciam as desigualdades de raça e etnia no contexto dos feminismos, enfatizando que a opressão atinge de forma mais direta e cruel as mulheres negras. A escrita de Angela Davis (2017, p. 17) traduz essa assertiva:

Proporcionalmente, as mulheres negras sempre trabalharam mais fora de casa do que suas irmãs brancas. $\mathrm{O}$ enorme espaço que o trabalho ocupa hoje na vida das mulheres negras reproduz um padrão estabelecido durante os primeiros anos de escravidão. Como escravas, essas mulheres tinham todos os outros aspectos de sua existência ofuscados pelo trabalho compulsório. Aparentemente, portanto, o ponto de partida de qualquer exploração da vida das mulheres negras na escravidão, teria uma avaliação desse papel como trabalhadoras.

Ao final do Século XX e no decorrer do Século XXI os movimentos vão se diversificando e muitas frentes vão emergindo e se articulando em grupos, fóruns, coletivos, das quais destacamos: Marcha Mundial de Mulheres, Articulação de Mulheres Brasileiras, Articulação de Mulheres Negras Brasileiras, Marcha das Margaridas, Rede Nacional Feministas de Saúde e Direitos Reprodutivos, Rede Feminista de Estudos e Pesquisas sobre Mulheres e Relações de Gênero, entre outras frentes.

Em suas análises sobre as diversas correntes do feminismo, Scavone (2004, p. 30) enfatiza que "[...] o que permaneceu como consenso político entre essas diversas correntes feministas contemporâneas foi o fato de contestarem o caráter irreversível da subordinação feminina nos planos teórico, político e prático.”. 


\section{Revista \\ Debates Insubmissos}

\subsection{A luta feminista vem de longe: uma brevíssima história do feminismo brasileiro}

Ao buscar as origens do feminismo no Brasil, os escritos sempre nos levam a duas figuras emblemática de Olympe de Gouges na França e Mary Wollstonecraft na Inglaterra que lutaram pela cidadania das mulheres e pelos direitos das mulheres à educação. No Brasil a pioneira do feminismo foi Nísia Floresta, potiguar, nascida em 1809, que se notabiliza por escrever em 1835 "Direitos das Mulheres, injustiças dos homens, livro que reflete o pensamento da inglesa Mary Wollstonecraff no qual faz críticas severas ao pensamento de Jean Jacques Rousseau:

Todos sabem que a diferença dos sexos só é relativa ao corpo e não existe mais que nas partes propagadoras da espécie humana; porém, a alma que não concorre senão por sua união com o corpo, obra em tudo da mesma maneira sem atenção ao sexo. Nenhuma diferença existe entre a alma de um tolo e de um homem de espírito, ou de um ignorante e de um sábio, ou a de um menino de quatro anos e um homem de quarenta. Ora, como esta diferença não é maior entre as almas dos homens e a das mulheres, não se pode dizer que o corpo constitui alguma diferença real nas almas. (FLORESTA, 1989, p.47).

Nísia Floresta defendia o direitos das meninas à educação, por considerar que, é através da educação, era possível construir um pensamento racional e crítico, assim a autora contestava o pensamento conservador e patriarcal de Rousseau quando este no seu livro Emílio enfatizava que as mulheres não tinham capacidade de pensar, dada sua condição de maternar e portanto de se emocionar. Em 1838, Nísia fundou o Colégio Augusto, o qual oferecia cursos para as meninas e moças. Ela escreveu ainda: Conselhos à Minha Filha” (1842), "Opúsculo Humanitário" (1853) e “A Mulher” (1856).

Entre as nossas pioneiras destacamos ainda a professora mineira Francisca Senhorinha da Mota Diniz, que lança em 1873 o jornal O Sexo feminino, que, após proclamação da República em 1889 passou a ser denominado O Quinze de Novembro do Sexo Feminino. Outros jornais iam sendo editados ao longo dos finais do Século XIX, dentre eles a Mensageira, editado em São Paulo pela jornalista Josefina Álvares de Azevedo (1851 - 1905), que em 1890 escreveu a peça teatral $O$ voto feminino; peça que repercutiu bastante no Rio de Janeiro e contribuiu enormemente para publicizar a luta pelo sufrágio. 
A luta das pioneiras foi protagonizada por muitas feministas entre as quais Bertha Lutz, Leolinda Daltro (1860-1935) que, inconformadas com a negação do voto feminino na Constituinte de 1891, composta somente de homens, se juntam a várias amigas e fundam, em 1910 o Partido Republicano Feminino. Bertha Lutz também cria a Fundação para o Progresso Feminino. Esses exemplos mencionados mostram a intensidade da luta pelo voto feminino no Brasil, conquistado em 1932 no governo de Getúlio Vargas. Vale ressaltar, ainda, que, em 1928 o governador do Rio Grande do Norte - terra de Nísia Floresta - concedeu o voto às mulheres e elegeu naquele ano a primeira prefeita do Brasil, Alzira Soriano. Embora tenha sido anulada essa eleição, ficou o registro da vontade e insistência das mulheres pelo direito à cidadania.

A partir da conquista do voto, o movimento sufragista vai abrindo novas frentes de luta, e nestas frentes de luta as anarquistas tiveram um papel importante no Brasil. Vale ler os livros da feminista Margareth Rago para saber mais da ação destas feministas no Brasil.

\subsection{Os sujeitos do feminismo no Brasil}

A literatura abordando a trajetória do feminismo no Brasil é bastante extensa; nela situam-se diferentes visões, nas quais estão presentes as diversas correntes e particularidades regionais que enriquecem e reforçam sua pluralidade. Autoras como Rago (2004), Costa (2009), Ferreira (2007, 2016), Oliveira (2005), Scavone (2010) destacam a visão do feminismo como um movimento político que, ao atuar em diferentes campos, promoveu mudanças visíveis na sociedade e se constituiu como passo inicial e referência para que grupos de mulheres feministas e não feministas fossem protagonistas de ações em diferentes regiões e instâncias do mundo social.

A ação do movimento feminista tanto na teoria como na prática, teve e tem uma função social eminentemente política, dado seu potencial profundamente subversivo, desestabilizador, crítico, intempestivo, assim como pela vontade que manifesta de tornar o mundo mais humano, livre e solidário, seguramente não apenas para as mulheres. (RAGO, 2004, p. 36).

O sujeito do feminismo são todas as mulheres que foram descobrindo e se rebelando contra uma sociedade que lhes negou o lugar no mundo, desvalorizando e negando seus saberes 
e práticas. Parte desse desconhecimento é fruto da posição ocupada pelas mulheres no mundo público, isso porque neste mundo as posições dominantes determinam o que deve ser visto, considerado, enaltecido, lembrado. O lugar público foi durante muito tempo negado às mulheres. É contra esta negação que o movimento feminista se insurge, este é um dos horizontes desse movimento: retirar as mulheres da invisibilidade nas várias esferas da vida pública e privada.

Ao denunciar as desigualdades de gênero, o movimento feminista foi e continua sendo um dos protagonistas privilegiado em diferentes ações políticas que, se por um lado denunciavam as relações de subalternidade em que viviam as mulheres brasileiras, por outro interferiam para que essas desigualdades fossem combatidas através de um conjunto de propostas encaminhadas em diferentes instâncias: federal, estadual e municipal e em diferentes espaços - partidário, sindical, refletindo desejos e insatisfações das mulheres e esforço conjunto para mudar as relações de gênero.

Estas ações foram em grande parte facilitadas pela atuação em redes que possibilitaram enfrentar os desafios desse país cujas distâncias foram sempre desafiantes. Para Ferreira (2007) a articulação de redes e os diferentes mecanismos de comunicação impulsionados pelas tecnologias da informação facilitaram trocas e deslocamentos permanentes para a formação de quadros dentro do movimento em diferentes regiões.

Desse modo, é importante destacar o trabalho desenvolvido pelas Rede Nacional Feminista de Saúde e Direitos Reprodutivos, Rede de Combate à Violência de Gênero, Rede Feminista de Mulheres Negras, Rede Feminista Norte e Nordeste de Estudos e Pesquisa sobre Mulher e Relações de Gênero (REDOR), Marcha Mundial de Mulheres, SOS Corpo e Cidadania, Sempreviva Organização Feminista (SOF), Centro de Estudos e Assessoria Parlamentar (CFEMEA), Articulação de Mulheres Brasileiras, e pelos diversos Fóruns Estaduais, a exemplo do Fórum Maranhense de Mulheres e o Fórum de Mulheres de Imperatriz. Apenas para citar uma parte dos grupos que se movimentam, atuam e se manifestam protagonizando a luta política como sujeitos das mudanças nas relações de gênero no País.

Neste contexto de golpe essas articulações de redes e vários outros grupos foram os porta-vozes do descontentamento das mulheres, que se manifestaram de diversas formas sobre a 
parcialidade, virulência e misoginia em todo o processo de impeachment de Dilma Rousseff e denunciaram o golpe misógino e machista, que refletiu um profundo retrocesso na política brasileira, nas instituições democrática e na sociedade.

Os movimentos sociais e os movimentos feministas em especial, tiveram clareza de que o processo do impeachment, sob o argumento de "pedaladas fiscais", não justificava a retirada da primeira mulher presidenta do País, eleita em 2010 e reeleita em 2014 com mais de cinquenta e quatro milhões de voto.

\section{O MOVIMENTO FEMINISTA E SUA REAÇÃO CONTRA O GOLPE DE 2016: um olhar}

As correntes de pensar os movimentos feministas determinam a linha de condução de suas lutas políticas. Ao analisar a ação dos movimentos feministas no Brasil, observa-se que as correntes marxistas, radical e feminismo negro, de certa maneira, dão o tom da luta política no atual contexto. Não cabe aqui neste texto "enquadrar" nenhum movimento, tendo em vista que no processo do impeachment, e após o mesmo, os movimentos criaram consensos em torno da luta contra o golpe, assim denominado pela maioria das articulações feministas. Pode-se então afirmar conforme registros apresentados neste texto que a luta política neste período foi marcado por atos de protestos, manifestos, passeatas, que encheu ruas e praças da maior parte das capitais e grandes cidades brasileiras. As imagens colhidas em várias redes sociais, blogs, sites, demonstraram a efervescência e o descontentamento das mulheres e a enorme repercussão que este movimento imprimiu ao golpe, mascarado de impeachment.

O protagonismo das mulheres em todo o processo nos mostra a clareza dos movimentos feministas e de mulheres que não aceitaram os argumentos apresentados pelo Congresso e pelos opositores de Dilma Rousseff para justificar sua saída sob o argumento de que teria cometido “pedaladas fiscais”. As feministas declararam a real dimensão do golpe: parlamentar, midiático, capitaneado pelo Supremo Tribunal Federal, que funcionou como um tribunal de exceção, e seguiu as ordens da elite econômica que se fez claramente presente pela Federação das Indústrias do Estado de São Paulo - Fiesp e seu pato amarelo, e, pelos seus adeptos, como 
Paulo Lemman $(2015)^{6}$, o homem mais rico do Brasil que se prevaleceu do golpe para aumentar mais ainda sua enorme fortuna com a compra de parte das ações da Eletrobrás, privatizada pelo governo de Temer, uma das primeiras medidas de seu governo largamente veiculado em diversas matérias publicadas ${ }^{7}$ na mídia a exemplo de Barrocal $^{8}$ que classifica a privatização de negociata.

A ação dos movimentos sociais entre os quais destacamos o Movimento dos Trabalhadores sem Terra (MST), Movimento Negro, Movimento pela Moradia nas ações contra o impeachment foram inúmeras. No que se refere aos movimentos feministas em especial, estes se fizeram presentes através de diversas organizações, entre as quais a Sempreviva Organização Feminista (SOF), Geledés Instituto da Mulher Negra, que em São Paulo organizaram inúmeras manifestações, escreveram manifestos denunciando o golpe e a intolerância de uma elite que não suportou os pequenos avanços alcançados pelos pobres no País. As imagens a seguir e a fala de Nalu Faria expressam o pensamento das feministas da Marcha Mundial de Mulheres e de outras organizações feministas do País em diversas localidades, como podemos observar nas figuras 1 e 2 .

Vimos o oligopólio da comunicação avançar ainda mais no seu papel de organização da mobilização da direita, do julgamento e condenação sumários. Vimos crescer a intolerância. A elite querendo voltar décadas atrás e se manifestando para que os pobres, os negros e as mulheres "voltassem para o seu lugar" (FARIA, 2016, p. 4).

Figura 1 - Feministas contra o Golpe de 2016

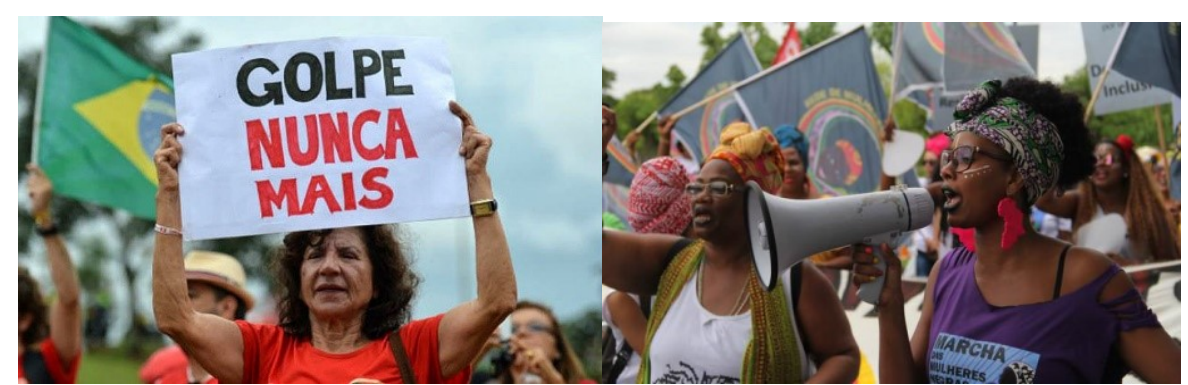

\footnotetext{
${ }^{6}$ Jorge Paulo Lemann é quem financia o golpismo? (2015)

${ }^{7} \mathrm{Na}$ privatização da Eletrobrás, incompetência e irresponsabilidade. Carta Capital. (2018)

${ }^{8}$ BARROCAL, André. O cheiro de negociata na privatização da Eletrobrás. Carta Capital. 2017
} 


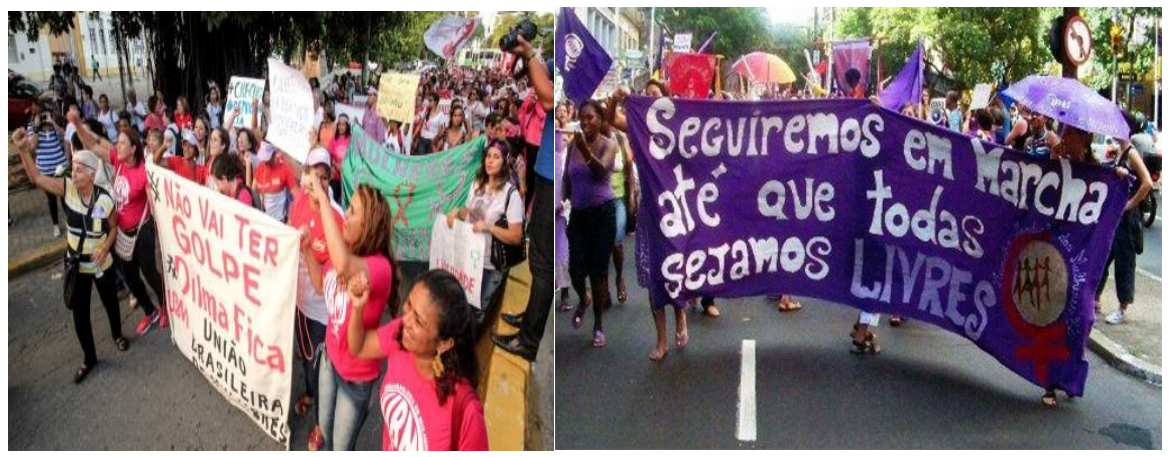

Fonte: SEMPREVIVA organização feministas (2017)

As imagens que encheram o Brasil de protestos mostraram não apenas $o$ descontentamento das mulheres, mas a criatividade dos feminismos de várias cores e de várias correntes onde expressam através de faixas, cartazes, palavras de ordem, frases, falas: os feminismos negros, os feminismos marxistas, os feminismos radical, os feminismos da diferença e da pluralidade.

Figura 2 - As ações das feministas negras

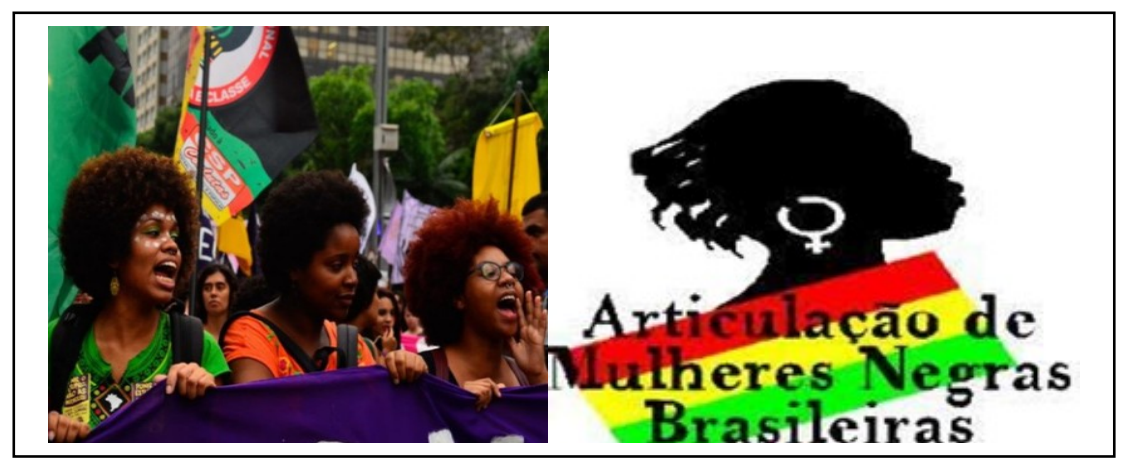

Fonte: ALBUQUERQUE, Naiara. (2017)

A Articulação de Mulheres Negras Brasileiras, organização que tem se pautado pela luta de enfrentamento ao racismo, ao sexismo e todas as formas de discriminação, lançou um manifesto em que traduz os descontentamentos deste segmento:

Repudiamos as iniciativas de impedimento da Presidente Dilma Rousseff, primeira mulher a governar o país, sem que se provasse qualquer crime de responsabilidade cometido por ela. Este processo é mais um atentado à democracia planejado e operacionalizado por uma oligarquia de homens brancos, velhos e ricos, que sempre atuou contra a vida e os direitos de mulheres e homens negras e negros, da juventude negra, das comunidades 


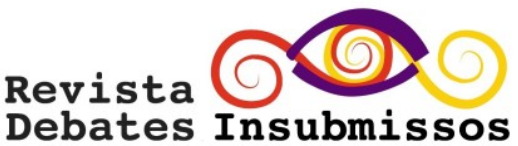

quilombolas e indígenas, de lésbicas, gays, trans, de religiosas e religiosos de matriz africana e de toda a população que luta por igualdade e justiça (MANIFESTO ..., 2016, p.1).

Nesta mesma linha de pensamento também se posicionou a Rede Nacional Feminista de Saúde Direitos Sexuais e Direitos Reprodutivos, cuja manifestação enfatiza que ao longo de três décadas de existência se pautou na defesa da democracia e do estado de direito, lembrou que foi graças à luta das organizações feministas que se conquistou uma série de direitos, entre as quais a Política Nacional de Atenção Integral à Saúde da Mulher (BRASIL, 2004) e a Lei Maria da Penha (BRASIL, 2004) reconhece que:

Não temos ainda a democracia que queremos, pois as mulheres são absoluta minoria nos espaços de poder e decisão. Ainda morrem por causas evitáveis e pela violência doméstica e de gênero. Entendemos que é preciso ampliar esta democracia, torná-la mais aberta e transparente, e que o modelo de desenvolvimento deve estar mais voltado à desconcentração da renda e numa perspectiva de sustentabilidade social e econômica. (REDE, 2016, p. 1)

Uma das articulações que realizou um dos movimentos mais singelos, com muita repercussão no cenário político, foi a Marcha das Margaridas que reuniu mais de 100 mil mulheres, muitas delas viajaram dias e noites enfrentando sol e chuva para estar presente no maior ato feminista que já se teve notícia no Brasil. O objetivo da Marcha é a luta pela reforma agrária, soberania alimentar, igualdade de direitos e o fím da violência contra a mulher. Esta Marcha que se reuniu pela $5^{\text {a }}$ vez em 2015 é uma referência a Margarida Maria Alves, líder camponesa assassinada pelo latifúndio em 1983. Margarida simboliza a luta das mulheres, pobres, das quilombolas, seringueiras e do campo. As imagens apresentadas na figura 3 indicam a grandeza do ato. 


\section{Revista 90 \\ Debates Insubmissos}

Figura 3 - Marcha das Margaridas protesta contra o golpe

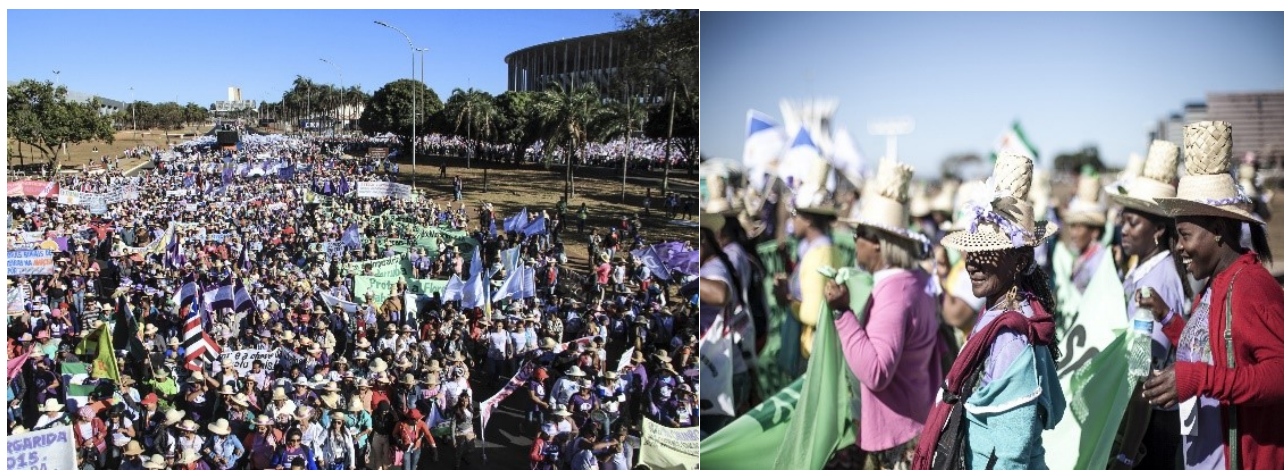

Fonte: STREIT, Maíra. (2015)

Essas mulheres, em toda as paradas da marcha, recordaram os ganhos obtidos no governo de Luiz Inácio Lula da Silva e Dilma Rousseff. Nesta edição, além de suas bandeiras comuns mencionadas, elegeram a luta contra o golpe como um tema central nesta manifestação histórica. O olhar de D’Emery (2015, p. 1) sobre a Marcha nos dá a real dimensão da intensidade da luta deste segmento:

As Margaridas tomaram conta de Brasília na última quarta (dia 12) com toda garra, força e energia para lutar por suas reivindicações por desenvolvimento sustentável com democracia, justiça, autonomia, igualdade e liberdade, denunciando as desigualdades sociais, todas as formas de violência, exploração e dominação. Mulheres de todos os biomas, idades, tipos de cabelo e donas do seu corpo disseram não ao retrocesso político e social. Dezenas e dezenas de milhares de companheiras mostraram que não existe governo democrático sem mobilização; sem uma articulação construída de forma coletiva; sem que as ruas sejam tomadas.

Em março de 2018 esta articulação lançou um Manifesto no qual reforçou a continuidade da luta contra o capitalismo, os racismos e o sexismo e expõe claramente os retrocessos que se sucederam após o golpe de 2016:

Somos milhões de Margaridas, mulheres lutadoras que fazem brotar nos campos, florestas e águas de todo o Brasil as formas de resistência, em defesa de um Brasil democrático, soberano e livre das opressões capitalistas, sexistas, racistas e de gênero. [...] A nossa marcha por direitos é, acima de tudo, uma marcha por democracia! Entendemos que o golpe político e os desmontes de direitos são duas faces de uma mesma moeda, que tem por base a precarização da vida e a entrega da nossa soberania ao capital nacional e internacional, agenda esta que vem se intensificando em toda a América Latina (MANIFESTO..., 2018, p. 1-3). 
A Articulação de Mulheres Brasileiras que agrega várias entidades feministas como CFEMEA, SOS Corpo e vários fóruns estaduais e municipais, entre os quais o Fórum Maranhense de Mulheres e o Fórum de Mulheres de Imperatriz, também lançou nota pública contra o golpe. Na nota "Não ao Governo da Coalizão Golpista!" lançado em maio de 2016 as feministas declararam:

Dilma está submetida a julgamento de exceção: é ainda Presidenta da República eleita, injusta e temporariamente afastada, mas o governo interino da coalizão golpista, setores do STF e a mídia golpista atuam como se já tivesse sido julgada e condenada... É O Golpe que serve aos interesses do capital, e tem forte caráter patriarcal e misógino. As elites nunca aceitaram ser governadas por uma mulher. A mídia golpista, aliada da colisão golpista, não aceita que mulheres participem da vida e das decisões políticas do país, nos querem 'recatadas e do lar', enquanto propagam as fotos do ministério golpista formado por homens brancos. A violência política contra a Presidenta, vivenciada em todo o processo, expressa um tipo de violência patriarcal que deve ser denunciada e combatida. (ARTICULAÇÃO ..., 2016, p. 1-2).

\section{Figura 4 - Mulheres se manifestam contra governo Temer e contra o golpe}

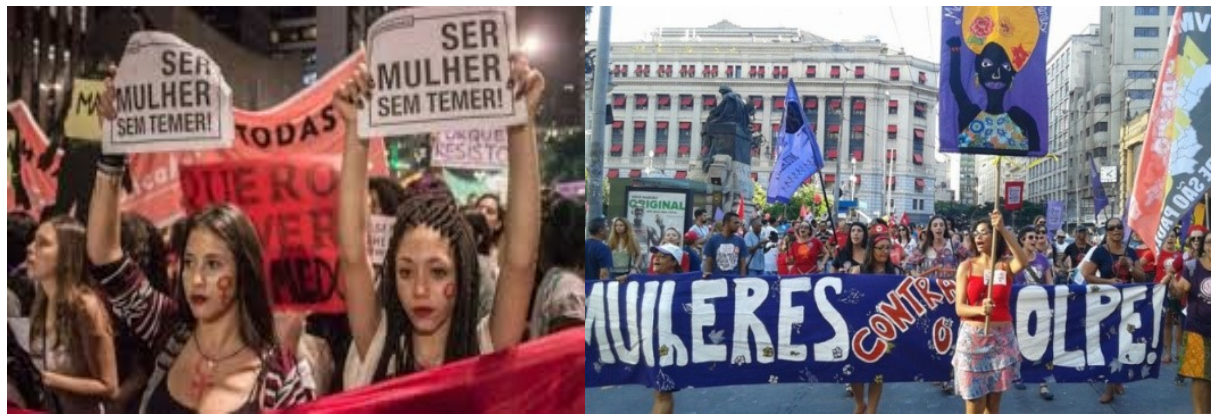

Fonte: MULHERES... (2016); MULHERES... (2016)

Os pequenos fragmentos das falas, manifestos e as imagens selecionadas neste texto, retratam as inquietações, lutas e descontentamentos, radicalidade deste movimento transgressor que, muitas vezes, tentaram silenciar. Não foram poucas as vezes que se ouviu: $\mathrm{O}$ que mais querem as mulheres? O que ainda falta conquistar? Esquecem que a frágil democracia brasileira, mesmo nos períodos de Luiz Inácio Lula da Silva e Dilma Rousseff ainda não conseguiu construir a equidade de gênero. 
O feminismo que perpassou o Estado através das ações da Secretaria Nacional de Políticas para as Mulheres avançou em muitos aspectos, mas não conseguiu superar problemas cruciais como a sub-representação das mulheres na política, a violência de gênero e inúmeras outras desigualdades como a salarial. Essas constatações nos leva a um questionamento feito por Eleonora Menecucci, ex-ministra de Dilma Rousseff:

O cenário político hoje no Brasil nos remete a uma pergunta crucial e estruturante sobre o protagonismo das mulheres nas diferentes cenas políticas: na vigência de um golpe patriarcal, machista, sexista, capitalista, fundamentalista, mediático e parlamentar que retirou da presidência da República a primeira mulher eleita e reeleita com mais de 54 milhões de votos, como ficam os direitos conquistados e a cidadania das mulheres? (MENECUCCI, 2016, p.2).

A resposta a essa pergunta pode ser refletida nos desdobramentos do impeachment: perda de direitos, aumento da violência de gênero, número acentuado de feminicídios, que reforçam a necessidade e urgência da intervenção do Estado.

A perda de status da Secretaria Nacional de Política para as Mulheres e a consequente diminuição de seu orçamento, inviabilizaram as políticas públicas que estavam em curso, fato que incide nos indicadores de violência, na sub-representação feminina e na agudização dos problemas decorrente das relações de gênero.

\section{ALGUMAS CONCLUSÕES EM PROCESSO}

Os desdobramentos desta luta que acompanha todo o processo do impeachment podem ser percebidos na forma como os debates fluíram naquele período. As universidades, partidos, sindicatos, grupos discutiram intensamente o golpe e suas consequências. Acreditávamos em algum momento, que poderíamos invertê-lo, embora sabendo que os espaços eram limitados.

Ao acompanhar a abertura do processo do golpe em 17 de abril de 2016, na Câmara dos Deputados, veiculado por todos os canais de televisão, percebemos que o processo todo era difícil de inverter. $\mathrm{O}$ espetáculo político mais caricato já visto no plenário daquela casa legislativa, denota o quão vergonhoso foi ouvir deputados defendendo suas famílias, seus redutos políticos, em nome de uma democracia que nenhum deles acreditava e que era visível 
em seus semblantes. Alguns deles tiveram que engolir sua afronta ao ser preso na semana seguinte por corrupção depois de declarar que votava pela ética.

Para Bethânia Ávila (2016, p. 3) “a situação se mostrou tão grotesca que todos os truques utilizados, para produzir os enganos, se mostraram inúteis".

O palco forjado para o ato final do golpe mostrou uma Dilma Rousseff segura, calma, íntegra, que enfrentou o processo até o fim, como num tribunal de exceção, semelhante ao que as mulheres viveram na inquisição, quando foram gradativamente queimadas, exterminadas da sociedade, pela sociedade conservadora que não aceitava seus poderes e seus saberes ancestrais. Estava claro que Dilma era inocente, e que as pedaladas fiscais não justificavam o impeachment. O que resultou foi a vergonha de uma sociedade que foi acordando lentamente da anestesia que a grande mídia proporcionou.

A reação dos movimentos feministas se fizeram ouvir em vários cantos do País, manifestando sua crítica, indignação e insubmissão. Praças e ruas se coloriram de lilás e vermelho, as redes sociais movimentaram milhares de mulheres. A forma como reagiram afirma o caráter transgressor deste movimento que saiu renovado deste processo com novas frentes e novas estratégias de mobilização, desta vez para eleger mais mulheres no pleito que se aproxima e que promete ser um momento de grande efervescência.

\section{REFERÊNCIAS}

ALBUQUERQUE, Naiara. O que querem os movimentos feministas que ocuparam as ruas do Brasil. Nexo Jornal. 8 mar. 2017. Disponível em: <https://www.nexojornal.com.br/expresso/2017/03/08/O-que-querem-os-movimentosfeministas-que-ocuparam-as-ruas-do-Brasil> Acesso em 23 jul. 2018.

ALVES, Branca Moreira. Ideologia e feminismo: a luta da mulher pelo voto no Brasil. Petropólis: Vozes, 1980.

APÓS impeachment, Senado transforma pedaladas fiscais em lei. Jornal do Brasil. 3 set. 2016. http://www.jb.com.br/pais/noticias/2016/09/02/apos-impeachment-senado-transformapedaladas-fiscais-em-lei/ Acesso em 23 jul. 2018. 
AVILA, Maria Betânia. Um golpe patriarca. SOS Corpo Instituto Feminista para a Democracia. 2016 Disponível em: http://soscorpo.org/um-golpe-patriarcal/. Acesso em 23 jun, 2018.

ARTICULAÇÃO de mulheres brasileiras na luta contra o golpe e contra a renúncia da presidenta Dilma Rousseff. 4 de maio de 2016. Disponível em:

$<\underline{\text { http://www.articulacaodemulheres.org.br/2016/05/04/articulacao-de-mulheres-brasileiras-na- }}$ luta-contra-o-golpe-e-contra-a-renuncia-da-presidenta-dilma-rousseff/> Acesso em: 25 jun. 2018.

BARROCAL, André. O cheiro de negociata na privatização da Eletrobrás. Carta Capital. 28 ago. 2017. Disponível em: https://www.cartacapital.com.br/politica/o-cheiro-de-negociata-naprivatizacao-da-eletrobras. Acesso em: 24 de jun. 2018.

BRASIL. Lei no 11.340, de 7 de agosto de 2006, [Lei Maria da Penha]. Brasília: Câmara dos Deputados, Edições Câmara, 2010. 34 p. - (Série ação parlamentar, n. 422). Disponível em: $<$ http://adcon.rn.gov.br/ACERVO/spmrn/DOC/DOC000000000076385.PDF>. Acesso 27 jun. 2018.

BRASIL. Ministério da Saúde. Secretaria de Atenção à Saúde, Departamento de Ações Programáticas Estratégicas. Política nacional de atenção integral à saúde da mulher: princípios e diretrizes. Brasília: Ministério da Saúde, 2004. 82 p.

CARTA da Articulação de Organizações de Mulheres Negras Brasileiras contra o Golpe de Estado em curso no Brasil. In: Racismo Ambiental, 8 jun. 2016. Disponível em: https://racismoambiental.net.br/2016/06/08/carta-da-articulacao-de-organizacoes-de-mulheresnegras-brasileirasamnb-contra-o-golpe-de-estado-em-curso-no-brasil/. Acesso 26 jun. 2018.

COSTA, Ana Alice. Feminismo brasileiro em tempos de ditadura militar. Labrys. estudos feministas/études féministes. 2009. Disponível em: <http://www.labrys15.net>. Acesso em: 23 jun. 2018.

DAVIS, Angela. Mulheres, raça e classe. Tradução Heci Regina Candiani. São Paulo: Boitempo, 2016.

D’EMERY, Nathália. Defesa da democracia dá o tom da $5^{\text {a }}$ Marcha das Margaridas. In: SOS Corpo: Instituto Feminista para a democracia. Disponível em: http://soscorpo.org/defesa-dademocracia-da-o-tom-da-5a-marcha-das-margaridas/>. Acesso em: 23 jun. 2018.

DILMA é inocentada pelas acusações de crimes Disponível em:.

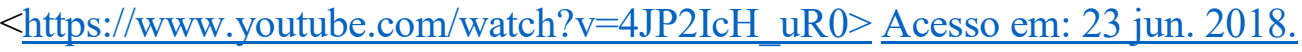

FABRINI, Fábio. Para Ministério Público, pedaladas do governo Dilma não são crime. O Estado de S. Paulo. 14 Jul. 2016. Disponível em:

$<\underline{\text { https://politica.estadao.com.br/noticias/geral,para-mp-pedaladas-do-governo-dilma-nao-sao- }}$ crime, $10000062862>$. Acesso em 26 jun. 2018 
FARIA, Nalu. A luta feminista contra o golpe patriarcal. In: Politizando: Boletim do Núcleo de Estudos e Pesquisas em Política Social (NEPPOS/CEAM/UnB), v. 6, n.22, p. 4-5, abr. 2016. Disponível em: $<$ http://www.sof.org.br/wp-content/uploads/2016/07/POLITIZANDO-n.22Abr.2016.pdf>. Acesso em: 23 jun. 2018.

FERREIRA, Maria Mary. As Caetanas vão à luta: feminismo e políticas públicas. São Luís: EDUFMA, 2007.

FERREIRA, Maria Mary. et. al. Direitos iguais para sujeitos de direito: empoderamento de mulheres no combate à violência doméstica. São Luís: EDUFMA, 2016.

FLORESTA, Nísia. Direitos das mulheres e injustiça dos homens. São Paulo: Editora Cortez, 1989.

JORGE Paulo Lemann é quem financia o golpismo? Brasil 247. 9 mar.2015. Disponível em: https://www.brasil247.com/pt/247/economia/172505/Jorge-Paulo-Lemann-\%C3\%A9-quemfinancia-o-golpismo.htm; Quem financia os grupos que pedem o impeachment?> Acesso em 20 jun. 2018.

KOLLONTAI, Alexandra Mikháilovna. Tradução de Denise Sales. A mulher trabalhadora na sociedade contemporânea. Pravda, n. 40, 1913. In: SCHNEIDER, Graziela. (Org.). A

Revolução das mulheres: emancipação, feminina na Rússia Soviética, artigos, atlas panfletos, ensaios. São Paulo: Boitempo, 2017, p. 150-163.

MANIFESTO da Marcha das Margaridas. Margaridas na luta por democracia e garantia de direitos. Brasília. 1 mar. 2018. Disponível em: $<$ http://www.contag.org.br/imagens/ctg_file 508242842 01032018101455.pdf $>$. Acesso em 27 jun. 2018.

MELO, Hildete Pereira de; THOMÉ, Débora. Mulheres e poder: histórias, ideias e indicadores. Rio de Janeiro: FGV Editores, 2018.

MENICUCCI, Eleonora. Como o golpe em curso impacta na vida das mulheres. Brasil 247. 27 de Jun. 2016. Disponível em: <https://www.brasil247.com/author/Eleonora+Menicucci> Acesso em 26 jun. 2018

MULHERES lutam contra impeachment sexista de Dilma, diz The Guardian. 7 jul. 2016. Disponível em: $<$ http://www.pt.org.br/mulheres-lutam-contra-impeachment-sexista-de-dilma-

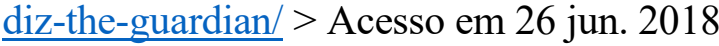

MULHERES vão às ruas em São Paulo contra golpe e machismo midiático. Frente Brasil Popular. 26 abr. 2016. <http://www.frentebrasilpopular.org.br/noticias/mulheres-vao-as-ruasem-sao-paulo-contra-golpe-e-machismo-midiatico-f2ed/ > Acesso em 26 jun. 2018. 
NA PRIVATIZAÇÃO da Eletrobrás, incompetência e irresponsabilidade. Carta Capital. 06/03/2018. Disponível em: $<$ https:/www.cartacapital.com.br/blogs/brasil-debate/privatizacaoda-eletrobras-incompetencia-e-irresponsabilidade> Acesso 26 jun. 2018.

OLIVEIRA, Eleonora Menicucci de. Nosso corpo nos pertence: uma reflexão pós anos 70. Labrys: estudos feministas/études féministes. Jan. /Jul. 2005.

PERÍCIA conclui que Dilma não participou de pedaladas fiscais. Disponível em: $<\underline{\text { http://g1.globo.com/jornal-nacional/noticia/2016/06/pericia-conclui-que-dilma-nao-participou- }}$ de-pedaladas-fiscais.html $>$. Acesso em 26 jun. 2018

PERROT, Michelle. As mulheres ou os silêncios da história. Tradução Viviane Ribeiro. Bauru: EDUSC, 2005.

QUEM financia os grupos que pedem o impeachment? Diário do Centro do Mundo. 13 mar. 2015. Disponível em: $<$ https://www.diariodocentrodomundo.com.br/quem-financia-os-gruposque-pedem-o-impeachment/>. Acesso em 26 jun. 2018.

RAGO, Margareth. Feminismo e subjetividade em tempos pós-modernos. In: COSTA, Cláudia de Lima; SCHMIDT, Simone Pereira. (Org.). Poéticas e políticas feministas. Ilha de Santa Catarina: Mulheres, 2004.

REDE Feminista contra o golpe: risco à democracia e à saúde das mulheres. 29 de mar. 2016. Disponível em: <https://claircastilhos.wordpress.com/2016/03/29/a-rede-feminista-e-osriscos-a-democracia-e-a-saude-das-mulheres/>Acesso: 27 jun. 2018.

SCAVONE, Lucila. Dar a vida e cuidar da vida: feminismo e Ciências Sociais. São Paulo: EDUNESP, 2004. 205p.

. Nosso corpo nos pertence? discursos feministas do corpo. Gênero. Niterói, v. 10, n. 2, p. 47-62, 1. sem. 2010. Disponível em: http://www.revistagenero.uff.br/index.php/revistagenero/article/view/4>Acesso: 27 jun. 2018.

SEMPREVIVA organização feministas imagens da luta contra o golpe promovido pelo sof (2017). Disponível em:

$<$ https://www.google.pt/search?q=Sempreviva+organiza $\% \mathrm{C} 3 \% \mathrm{~A} 7 \% \mathrm{C} 3 \% \mathrm{~A} 3 \mathrm{o}+$ feministas + ima gens $++\mathrm{da}+$ luta + contra $+\mathrm{o}+$ golpe + promovido + pelo + sof $\&$ tbm $=$ isch \& tbo $=u \&$ source $=$ univ $\& s a=X$ \&ved=2ahUKEwjI24q16f3cAhUS31MKHfkYArcQsAR6BAgCEAE\&biw=1094\&bih=478> Acesso em 27 jun./ 2018.

STREIT, Maíra. Marcha das Margaridas reúne 100 mil mulheres em apoio a Dilma. 12. Ago. 2015. Disponível em: $<$ https://www.cartamaior.com.br/?/Editoria/Politica/Marcha-dasMargaridas-reune-100-mil-mulheres-em-apoio-a-Dilma/4/34226> 
Revista

Debates Insubmissos

WALLERSTEIN, Waleska. Feminismo como pensamento da diferença. Labrys: Estudos Feministas/études féministes, Jan./jun. 2004. Disponível em:

$<$ https://www.labrys.net.br/labrys5/textos/valeskafeminismo.htm> Acesso em: 23 jun./ 2018.

Submetido em: 02/07/2018

Aprovado em: 22/08/2018 